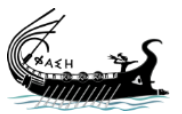

journal. phaselis.org

\title{
Bir Ortaçă̆ Anadolu Kenti Olan Castel Lombardo ya da Castel (Cape) Ubaldo'nun Konumu Üzerine bir Değerlendirme
}

\author{
An Assessment on Location of Castel Lombardo or Castel \\ (Cape) Ubaldo as a Medieval Anatolian City
}

Mehmet Ali BOZKUŞ

open 2 access journals

The entire contents of this journal, Phaselis: Journal of Interdisciplinary Mediterranean Studies, is open to users and it is an 'open access' journal. Users are able to read the full texts, to download, to copy, print and distribute without obtaining the permission of the editor and author(s). However, all references to the articles published in the e-journal Phaselis are to indicate through reference the source of the citation from this journal.

Phaselis: Journal of Interdisciplinary Mediterranean Studies is a peer-reviewed journal and the articles which have had their peer reviewing process completed will be published on the web-site (journal.phaselis.org) in the year of the journal's issue (e.g. Volume II: JanuaryDecember 2016). At the end of December 2016 the year's issue is completed and Volume III: January-December 2017 will begin.

Responsibility for the articles published in this journal remains with the authors.

Citation M. A. Bozkuş, "Bir Ortaçağ Anadolu Kenti Olan Castel Lombardo ya da Castel (Cape) Ubaldo'nun Konumu Üzerine bir Değerlendirme". Phaselis III (2017) 259-269.

http://dx.doi.org/10.18367/Pha.17015

Received Date: 18.09.2017 | Acceptance Date: 13.10.2017 | Online Publication Date: 13.12.2017

Editing Phaselis Research Project www.phaselis.org 


\title{
Bir Ortaçağ Anadolu Kenti Olan Castel Lombardo ya da Castel (Cape) Ubaldo'nun Konumu Üzerine bir Değerlendirme
}

\author{
An Assessment on Location of Castel Lombardo or Castel (Cape) Ubaldo as a Medieval \\ Anatolian City
}

\author{
Mehmet Ali BOZKUŞ*
}

Öz: Bu çalışmada birbiriyle ilgili iki farklı konu incelenmektedir. Illk olarak Ortaçağ deniz haritalarında Alanya'ya komşu bir kent olarak gösterilen Castel Lombardo veya Castel (Cape) Ubaldo ele alınmıştır. Aslında kentin ismi Castel Lombardo'dur ve yüzyıllar içinde Castel (Cape) Ubaldo'ya dönüşmüştür, buna rağmen bu iki isim iki farklı yer olarak algılanmış, bu da günümüze değin devam eden bir karışıklğın doğmasına neden olmuştur. Amacımız ilk olarak bu karışıklığı gidermektir. ỉkinci olarak ise, kentin bugün neresi olduğunu saptamaktır. Araştırmacılar, farklı yerler olarak algıladıkları Castel Lombardo/Castel Ubaldo için iki farklı tahminde bulunmuşlardır. Bazı istisnalar olmasına rağmen Castel Lombardo için Selinti, Castel Ubaldo içinse Alanya işaret edilmektedir. Bu çalışmada ise diğer görüşleri ve kendi bulgularımızı karşılaştırarak, kentin bugünkü konumunun neresi olabileceğine dair düşüncelerimizi açıklayacağız.

Anahtar sözcükler: Castel Lombardo, Castel (Cape) Ubaldo, Alanya, Selinti, lotape

Abstract: In this study two different issues intertwined with each other are examined. Firstly, in Medieval sea maps, Castel Lombardo and Castel (Cape) Ubaldo, which are shown as a neighboring city to Alanya, were studied. Despite the fact that Castel Lombardo in the maps turned into Cape Ubaldo in time, these two names were perceived as two different places, which led to the ongoing controversy even still today. Our goal first and foremost is to clarify this confusion. Secondly, it is to determine where the city is located today. The researchers made two different estimates for Castello Lombardo/Cape Ubaldo, which they perceive as two different places. Although there are some exceptions, Alanya for Castel (Cape) Ubaldo, and Selinti for Castello Lombardo are pointed out. In this study, based on all these evaluations and with our own findings, our thoughts about where the present location of this city is will be explained.

Keywords: Castel Lombardo, Castel (Cape) Ubaldo, Alanya, Selinti, lotape

\section{Giriş}

Memluklerin 1289'da Trablus'u ve 1291'de Akka'yı fethetmesi, Papalığı, Müslümanlarla yapılan ticarete ambargo koymaya itti. Papalık sürekli yayınladığı kararnamelerle bu ambargoyu, çoğu zaman sadece silah, demir, kereste ve köle ticaretini kapsayacak şekilde, yüzyıllar boyunca sürdürdü ${ }^{1}$. Yasağı uygulayabilmek için de Doğu Akdeniz'de bir filo oluşturuldu. Ancak bu filo gerekenleri tam olarak yapamadı, çünkü Müslümanlarla ticarete devam etmek isteyen Batılı tüccarlar, Kilikya ve Likya sahillerinin girintili çıkıntılı yapısından faydalanıp, kontrol filosundan

\footnotetext{
* Yrd. Doç. Dr., Hitit Üniversitesi, Fen-Edebiyat Fakültesi, Tarih Bölümü, mehmetalibozkus@hotmail.com

1 Poumarede 2010, 280.
} 
kaçmak için gizli demir atma yerleri buldular². Kıyı şeridindeki Portus Pisanorum (Pisalıların), Portus Prodensalium (Provensallerin) ve Portus Januensis (Cenevizlilerin) limanları bu türden yerlerdi ${ }^{3}$. Castel Lombardo da Pisa ve Cenevizlilerin de demir attı $\breve{g}^{4}$, kontrol filosundan kaçabilmek için gizli ve güvenli bir limandı. Fakat zamanla bölge terk edilip kale harap hale geldi ${ }^{5}$. Kentin ismi ise XIII. ve XIV. yüzyıllardan kalma bir anı olarak yaşamaya devam etti. XVII. yüzyıla gelindiğinde Castel Lombardo ismi değişerek Castel (Cape) Ubaldo'ya evrildi ${ }^{6}$. Gerçekten de deniz haritaları geçmişten günümüze doğru incelendiğinde, kentin isminin Castel Lombardo'dan Castel Ubaldo'ya, dönüştüğü ortaya çıkmaktadır. Castel Lombardo kelimesi XVI. yüzyıl ortalarından itibaren Castelonbaldo'ya ve son olarak Castel (Cape) Ubaldo'ya dönüşmüştür. Antalya Körfezi'nin doğusunu kapsayan, tarihsel olarak geçmişten günümüze doğru sıraladığımız 16 harita parçasında, zamanla meydana gelen bu değişim daha net görülmektedir ${ }^{7}$ (Fig. 7-22). Sonuç olarak rahatıkla söylenebilir ki, iki ayrı kent yoktur sadece, ismi Castel Lombardo'dan, Castel (Cape) Ubaldo'ya dönüşen tek bir kent vardır.

Kentin ismindeki dönüşüm daha önce tam olarak anlaşılamadığından ileride daha detaylı açıklayacağımız üzere, Castel Lombardo'nun Selinti (Selinus, Gazipaşa), Castel (Cape) Ubaldo'nun ise Alanya (Candelor-Coracesium) olduğuna dair tahminler ileri sürülmüştür. R. Mason da bu soruna değinmiş, araştırmacıları farklı tahminlere yönlendiren bu iki ismin aynı yer olması gerektiği üzerinde durmuştur. Fakat kentin bugün neresi olabileceği konusunda bir sonuca ulaşılamadığı görülmektedir ${ }^{8}$.

\section{Castel Lombardo ya da Castel (Cape) Ubaldo'nun Konumu Üzerine Yapılan Çalışmalar}

Burada kentin konumunun neresi olduğuna dair yapılan araştırmaları tarihsel olarak sıralayacak olursak, ilk olarak F. Beaufort'u ve Cape Ubaldo'yu zikretmek gerekmektedir. O, eserinde D'Anville ${ }^{9}$ ve Galiano'nun ${ }^{10}$ haritalarından hareketle, Cape Ubaldo'nun Alanya-Cilvarda Burnu olması gerektiğini belirtmiş ve Alanya halkının da bu isme dair hiçbir bilgisi bulunmadığını, biraz da teessüfle ifade etmiştir ${ }^{11}$. W. M. Leake de, Alanya'nın eski haritalarda Castel Ubaldo olarak adlandırıldığını belirtmektedir ${ }^{12}$. Beaufort ve Leake'in benzer bir tahmine yönlenmesi muhtemelen Candelore'nin, Alanya'nın Ortaçağ' daki adı olduğunu fark etmemelerinden kaynaklanmaktadır.

Flemming 1964, 63.

Flemming 1964, 63-64.

Tomaschek, 1891, 57; Flemming 1964, 64.

Piri Reis XVI. yüzyılda bölgeden geçtiğinde kaleyi harap olarak kaydetmiştir. Piri Reis 2002, 761.

Haritalarda ve metinlerde geçen isimler şu şekildedir: Castel Lombardo-Castellombardo-Castel LombardCastrum Lombardum-Castel Lonbard-Castello Bernardo-Castelonbaldo-Castel Ubaldo ya da LombardorC.Ubalde-Chau Lombard- Cast. Ubaldo-Cast Lombardi v. Ubaldi-Cap Baldo-Cap Ubaldo-Cape Ubaldo.

7 Haritalar seçilirken genellikle çevrimiçi kaynaklar kullanılmıştır. Bir eksiklik olarak belirtmek gerekirse kullanılan haritalar ve haritacılar makale ile ilgili olanlardır ve genel olarak birbirleriyle bir kıyaslamaya tabi tutulmamıştır. Ancak konu üzerine oluşmuş literatürde kullanılan tüm haritalara ve makaleye katkı yapacak diğer haritalara burada yer verilmeye çalışı ııştır.

8 Mason 1989, 94.

9 Jean Baptiste Bourguignon d'Anville (1697-1782). (Fig. 19).

10 Dionisio Alcala Galiano (1760-1805).

11 Beaufort 1818, 175-176; Hellenkemper ve Hild de Beaufort'tan hareketle Alanya'nın isminin XVIII. yüzyıl haritalarında Cape Baldo/Cape Ubaldo'ya dönüştüğünü belirtmektedirler. Hellenkemper-Hild 2004, 588.

12 Fakat Leake, Beaufort'da geçen Cape (burun) kelimesi yerine Castel (kale) kelimesini tercih eder, çünkü bazı haritalarda C. Ubalde yazılıdır, buradaki c. harfi aslında castel kelimesini ifade etmesine rağmen, ilginç bir şekilde Beaufort'ta cape (burun) şekline bürünmüştür. Leake 1824, 126; Leake'nin görüşü aynı şekilde William Smith editörlüğünde hazırlanan sözlükte tekrarlanmaktadır. Smith 1854, 668. 
Eserlerinde Candelore'ye hiç değinmemeleri bu fikri güçlendirmektedir. Çünkü yararlandıkları haritada Castel Ubaldo, Candelore (Alanya)'nin doğusunda çizilmiştir ${ }^{13}$ (Fig. 19).

Yaklaşık bir buçuk asır sonra, S. Lloyd ve D. S. Rice da: "Gerek Katalan haritası, gerek diğerlerinde Alanya burnu "Cap Ubaldo" ve "Cap Baldo" şeklinde adlandırılmaktadır. Bu herhalde bir gemicinin adına izafeten verilmiş olmalı, çünkü vekayi-namelerde böyle bir isme rastlanmamaktadır" diyerek, kent için Alanya'yı işaret etmişlerdir ${ }^{14}$. Fakat bahsedilen Katalan ve diğer haritalarda Cap Baldo ismi yerinde Castel Lombardo yazsa da (Fig. 7-8-9 vd.), muhtemelen Lloyd ve Rice'ı da hataya iten Beaufort ve Leake'in yorumlarıdır ${ }^{15}$. Çünkü Lloyd ve Rice'ın, Beaufort ve Leake'in Cape Baldo'nun Alanya olması gerektiğine dair hatalı olan fikrini tekrarladıkları görülmektedir.

Castel Lombardo'nun adının bir şekilde C. Ubaldo'ya dönüşümü, burasının Alanya olma ihtimalini ortadan kaldırmaktadır. Çünkü eklediğimiz harita parçaları incelendiğinde Castel Lombardo, Alanya'dan (Candelore) biraz daha doğuya konumlandırılmaktadır. Dolayısıyla Castel Lombardo ya da Castel Ubaldo'nun daha doğuda, başka bir yer olması gerekmektedir. Bu nedenle Alanya'nın yaklaşı 40 km doğusundaki Selinti'nin Castel Lombardo olduğu fikri ileri sürülmüştür. L. Alishan, kenti her ne kadar Alanya olarak kabul etse de ${ }^{16}$, bazı coğrafyacıların Selinti ya da buraya yakın bir yer olması gerektiğine dair iddialarına değinmiştir ${ }^{17}$. F. Hild ve $\mathrm{H}$. Hellenkemper de Ortaçağ deniz haritalarındaki Castel Lombardo'yu Selinti olarak kabul etmektedirler ${ }^{18}$.

W. Heyd bu konuda bir yorumda bulunmaz fakat burasının Alanya olamayacağına değinir ${ }^{19}$. W. Tomaschek ve Ortaçağ portolanları üzerine çalışmasıyla tanınan K. Kretschmer'in ise biraz kararsız olduğu görülmektedir. Çünkü XIII. yüzyıl sonlarında çizilen Carte Pisane'de geçen ve Castel Lombardo'nun doğusunda yazılı olan Salmonde'nin (Selinunde) (Fig. 7), Selinti olabileceği intimalini de düşünmektedirler ${ }^{20}$. Ayrıca Salmonde, bölgeyi iyi tanıyan Marino Sanudo'nun

13 Haritada yapılan bazı hatalar da, bir karışıkı̆̆ın doğmasına sebep olmuştur. Beaufort'un yararlandığı D'Anville tarafından yapılan haritada Candeloro, Alanieh, ve C. Ubaldo sıralı olarak yer almaktadır. Mason 1989, 94. dp26.

14

15 -Rice 1989, 6

Mason 1989, 94.

Alishan 1899, 373-374.

Alishan 1899, 375-377.

18 Hild-Hellenkemper 1990, 407.

19 Heyd 1885, 574, dn.6.

20 K. Kretschmer Castel Lombardo'nun Selinti olması gerektiğini söylemekle birlikte Salmonde için de “belki de Selinti” olabilir ifadesini kullanır. Bu nedenle kararsı olduğunu söylemek mümkündür. (Kretschmer 1909, 667). En detaylı tasviri Tomaschek yapmaktadır. Tomaschek Carte Pisane'deki ve Marino Sanudo'nun bahsettiği Salmonde'yi Selinti olarak kabul ettiğinden Castel Lombardo'yu Alanya-Selinti arasında aramaktadır. Kestel Suyu'na (muhtemelen Dim Çayı) dikkati çeker ve nehrin çevresindeki Leartes, Syedra ve lotape'ye değinir. (Tomaschek 1891, 57-58; Mason 1989, 94) Gerçekten de, Tomaschek'in belirttiği gibi isim benzerliğinden dolayı Kestel-Castel ve oradaki Buzağııı Kalesi akla gelmektedir. Dim Çayının ağzında bulunan bu kalenin etrafı duvarlarla çevriliydi ve içindeki yapı da Gülefşen'deki Selçuklu Beylerinin yaptırdığı kasra çok benzerlik gösteriyordu. Bu kale Evliya Çelebi bölgeden geçerken ayaktaydı ve halk buraya hayvanlarını koyduğu için Buzağılık Kalesi olarak adlandııılıyordu. İbrahim Hakkı Konyalı'nın 1940'lardaki ziyaretinde yapı hala duruyor ve batı duvarının dayandığı kilise harabesi görülebiliyordu. İ. H. Konyalı’nın kaleyi tasvirini burada aktarmakta fayda vardır: "Dim çayının kenarında bir tarafını çayın, üç tarafını kalın harçı taş duvarın çevrelediği, geniş sahanın ortasında iki katlı bir yapı harabesi vardır. Yapı Gülefşan'daki kasra çok benzer, plân hemen hemen aynıdır. Fakat bunun duvarları daha kalındır. Bina doğudan batıya doğru uzanmaktadır. Kapısı kuzeye açılır. Alt katında sağda beşik örtülü bir uzun kısım, bunun solunda da yine beşik örtülü dar bir kısım vardır. Binanın uzunluğu 12, eni 8 metredir... Hiç bir yerinde kitâbesi olmadığı için yaptıranı ve yapıldığı tarihi kesin olarak 
$1300^{\prime}$ lerin başında yazdığı eserinde de geçmektedir ${ }^{21}$. Hild ve Hellenkemper de Salmonde'ye değinirler, ancak başka haritalarda Salmonde'nin yer almadığının vurgusunu yaparlar ${ }^{22}$. Gerçekten de XVII. yüzyıla değin haritalarda, Castel Lombardo'dan sonra Antiocheia kenti yer almaktadır. Carte Pisane'nin haricinde bulabildiğimiz bir haritada Castel Lombardo ile Antiocheia arasına bir kent girmiştir, ancak bu kentin ismi okunamamaktadır (Fig. 12). Çok fazla kanıt olmasa da hem Carte Pisane'de (Fig. 7) hem de bölgeyi iyi tanıyan Marino Sanudo'nun eserinde Castel Lombardo'nun doğusunda Salmonde isimli bir kentten bahsedilmesi Castel Lombardo'nun Selinti olma intimalini zayıflatmaktadır. Ayrıca geç dönemde olsalar da, XVII. yüzyıl ile birlikte çizilen haritalarda Selinti ve Castel Lombardo/C. Ubaldo birbirinden ayrı yerler olarak çizilmeye başlanmıştır. Aslında bazı noktalarda hatalı ve karışık bilgiler intiva etseler de $\mathrm{e}^{23}$, bu haritaları incelediğimizde Castel Lombardo/C. Ubaldo'nun Alanya ile Selinti arasında yer aldığı görülmektedir (Fig. 18-19-21). Ancak neresi olduğunu bu haritalara bakarak tahmin etmek zordur. Sadece Alanya veya Selinti olmadığına dair fikir yürütmeye imkân vermektedirler.

\section{Piri Reis'in Castel Lombardo Tasviri ve Kentin Konumu}

Peki, bu kent tam olarak neresidir? Sorunun cevabını batıda çizilmiş ortaçağ portolanlarında bulmak mümkün değildir. Bu nedenle kent ile ilgili en önemli yazılı kaynağı incelemek gerekmektedir. Bu kaynak Piri Reis'in Kitabı Bahriye adlı eseridir ${ }^{24}$. Her ne kadar Piri Reis kendi haritasını

söylemeğe imkân yoktur... Kasrın batı tarafındaki avlu duvarı bir kilise harabesine dayanmaktadır." (Konyalı 1946, 361 - 362); Bugün kaleyi çevreleyen duvarlar halen ayaktadır ve duvarın dayandığı kilise seçilebiliyor, ancak içindeki yapıya dair bir iz kalmamıştır. (Redford 2008, 74); Ancak isim benzerliğinden dolayı ilk olarak akla gelen Kestel Buzağılık Kalesi'nin ihtimaller arasından çıkmasına ileride açıklayacağımız üzere Piri Reis'in tanımları engel olmaktadır.

21 Marino Sanudo, döneminin iyi bir gözlemcisidir. Kıbrıs, Mısır, Suriye ve Anadolu'ya defalarca seyahat etmiştir ve bölgeyi çok iyi tanımaktadır. Sanudo kadar eserinde Salmonde isimli bir kentten bahsetse de, kentin konumunu Carte Pisane'nin aksine, muhtemelen hatalı olarak Antiocheia'nın doğusunda göstermektedir. Fakat Castel Lombardo'nun (Castrum Lomshoaldum) konumunu doğru vermektedir. Sanudo'nun güzergahı: “Deniz yolculuğu ile, Kalandrus'tan Salmade 25 mil, Salmade'den Anthioceta 20 Mil, Anthioceta'dan Castrum Lomshoaldum (Lombardum) 25 mil, Castrum Lomshoaldum'dan Candelorus (Alanya) 10 mil." Sanudo 2011, 148.

22 Hild-Hellenkemper 1990, 407.

23 XVII. yüzyıl ile birlikte çizilen haritalar incelendiğinde birçok hata dikkati çekmektedir. Örneğin Pierre Duval haritasında (Fig. 15) Side, Candeloro'nun doğusuna çizilmiştir. Bir diğer örnek D’Anville'nin (Fig 19) Beaufort’u da yanıltan haritasında görülmektedir. Burada da Candelor ile Alanya birlikte ayrı ayrı yerlermiş gibi verilmektedir. İleride açıklayacağımız üzere bir başka hata ise Piri Reis'in haritasında görülmektedir. Piri Reis haritalarının yanı sıra çizdiği bölgelerle ilgili açıklamalar da yazmıştır. Fakat anlattı̆̆ımız bölgeyi kapsayan açıklamaları ile çizdiği haritası birbirini tam olarak tutmamaktadır. Açıklamalarının aksine haritasında Selinti Suyu'nu daha doğuya çizmiştir. Sonuç olarak bu tarihsel haritalarda açıkladığımız şekildeki yanlışıkların sık yapıldığını belirtebiliriz. Bu dönem haritaları hakkında daha fazla bilgi için bkz. Duggan, 2017, 1-48.

24 Kitab-ı Bahriye'nin 927/1521 ve 932/1526 tarihlerinde tertip edilmiş iki farklı nüshası bulunmaktadır. Bu nüshaların günümüze ulaşanlarının sayısı yaklaşık altmış kadardır. 932/1526 tarihinde tertip edilenler ikinci telif olarak bilinmektedir ve bunlarda ilk teliflerde olmayan manzum bölümler ve haritalar bulunmaktadır. Son şeklini alıncaya kadar eserin Piri Reis tarafından geliştirildiği anlaşılmaktadır. İinci telifler arasında İstanbul Süleymaniye Yazma Eserler Kütüphanesi Ayasofya Koleksiyonunda bulunan 2612 numarada (34 SüAy 2612) kayıtı nüsha "en tam ve mükemmeli" olarak tanımlanmaktadır. Bu nüsha iki defa tıpkıbasım, bir defa da sadeleştirilerek yayınlanmıştır. Bu çalışmada hem yayımlanmış baskılar hem de orijinal nüsha görülmüştür. Bununla birlikte The Walters Art Museum'da bulunan nüsha (http://art.thewalters.org/files/pdf/ W658.pdf) ile İstanbul Atatürk Kitaplığında bulunan Muallim Cevdet Yazmaları 30 (Mc Yz O0030) numaralı Kitab-ı Bahriye nüshaları da incelenmiştir. Ancak nüshalar arasında konuyla ilgili bölümlerde bir farklılık olmadığı görülmüştür. Bu nedenle metinde atıflar, Türk Tarih Kurumu tarafından 2002 yılında yayımlanan Ayasofya 2612 numaralı nüshaya yapılmıştır. Kitab-ı Bahriye nüshaları için bk. Sarıcaoğlu 2002, 72-75. Ayasofya 2612 numaralı nüshadan hareketle yapılan basımlar için bk. Piri Reis, Kitabı Bahriye, Türk Tarih 
çizerken yazdıklarının aksine Selinti Suyu'nu (Musa Çayı-Selinus Potamos) yanlış yere, daha doğuya konumlandırsa da ${ }^{25}$, yazdıklarıyla kentin tasvirini yapmıştır. Onun tasvirleri kentin neresi olabileceğine dair ipuçları sunmaktadır. Anamur'dan Alanya'ya doğru seyahat eden Piri Reis Castel Lombardo'ya değin güzergâhı şu şekilde anlatır: "Mezkûr Kaladıran (Yakacık-Calandro) bir körfezdir ... ve onun gün batısı tarafında (batısında) bayıra karşı bir yüce yerde bir harap kale vardır. Ol kaleye Kızlar Hisarı derler. Mezkur hisarı tekrar gün batısı tarafına dolaştık da Selindi Suyu derler bir su akar ... ve o suyun tekrar gün batısı tarafında Ahmedce derler deniz üzerine havale (sarkmış) ada gibi bir yumru burnun üzerinde bir harap kale vardır. Ol kaleye Efrenç taifesi Kastalo Lombarda derler. Yani Top Hisarı demek olur. Vakı'a top taşı misalinde bir yumru burunun üzerinde vaki olmuştur, mezkûr kaleden Alâ'iyye yirmi mildir"26.

Bu anlatım şu şekilde bir güzergâh çizilmesine neden olmaktadır. Güneydoğudan, kuzeybatıya: Kaledıran - Kızlar Hisarı - Selinti Suyu - Ahmedce Kalesi (Kastalo Lombarda) Alâiyye (Alanya). Ancak daha önce belirttiğimiz gibi, haritada bu sıralamaya aykıı ve yanlış olarak Selinti Suyu Kızlar Hisarı'nın doğusuna konumlandırımışııı ${ }^{27}$ (Fig. 1). Piri Reis'in yazdıklarına ters olduğu için haritadaki Selinti Suyu'nun konumunu bir hata olarak kabul edersek, şu soruya cevap aramamı gerekiyor. Eğer Castel Lombardo, Selinti Kalesi ise Piri Reis neden Selinti Suyu'ndan bahsediyor da, aynı yerde daha batıya gitmeden, kaleden bahsetmiyor? Eğer Castel Lombardo, Selinti olsaydı, Selinti Suyu'nun hemen dibinde ve konum olarak doğusunda olan kaleden bahsetmesi gerekmez miydi?

Elbette kaleden bahsetmemesinin birden çok sebebi olmalıdır. Illk olarak şunu ifade etmek gerekir; Piri Reis, denizcilerin yollarını kolayca bulabilmeleri için dikkat çeken nişanlardan (izlerden) bahsetmiştir. Zira Selinti Kalesi deniz tarafından bakıldığında, üzerinde bulunduğu kayalığın açısı nedeniyle görülebilir bir yerde değildir, iç yamaçtadır (Fig. 2). Dolayısıyla Piri Reis kaleyi görmemiş olabilir. Piri Reis'in Selinti Kalesi hakkında sessiz kalmasının aslında bu makalenin iddiasını zayıflatan bir yönü vardır. Akla şu eleştiri gelebilir: Eğer Piri Reis Selinti Kalesi'ni fark etseydi, belki de orasının Castel Lombardo olduğunu belirtecekti. Ancak böyle bir intimal, yazarın bölge ile ilgili bir bilgisi olmadığını kabul ettiğimiz zaman mümkün olabilir. Fakat bunun aksine Piri Reis'in tasvirlerinden ve kullandığı ifadelerden bölgeyi tanıdığı anlaşılmaktadı ${ }^{28}$.

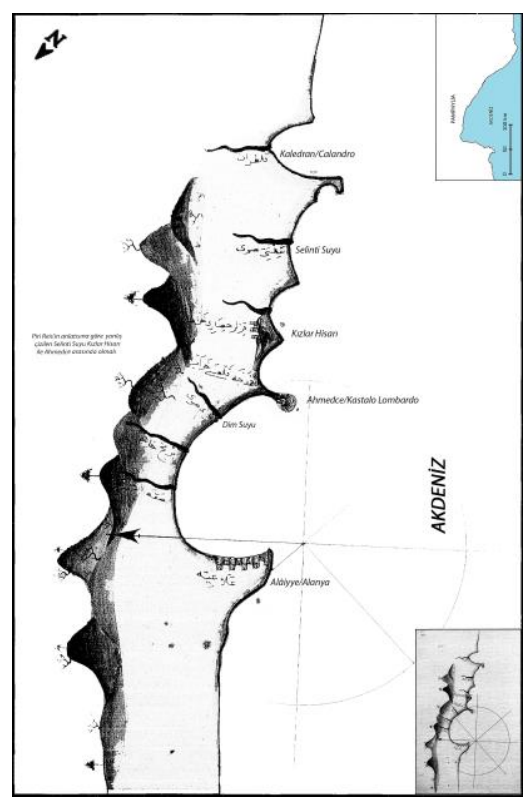

Fig. 1. Piri Reis, Kitabı Bahriye (2002), Kaledıran'dan Alanya'ya kadar sahil şeridi.

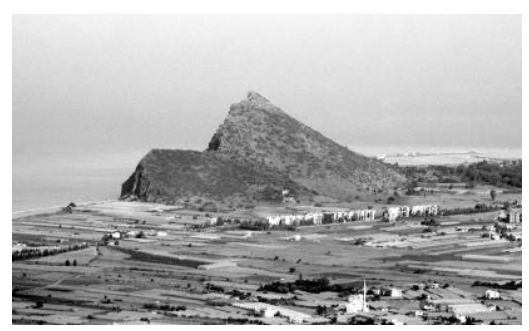

Fig. 2. Selinti Rauh et al. 2009, 286.

Kurumu, Ankara 2002; Pirî Reis, Kitab-ı Bahriye, ed. Ertuğrul Zekâi Ökte, Kültür ve Turizm Bakanlığı, İst. 1988; Pîrî Reis, Kitâb-ı Bahriyye, Haz. Yavuz Senemoğlu, C.I-II, İst. 1974.

25 Hild-Hellenkemper 1990, 408.

26 Piri Reis 2002, 760.

27 Piri Reis 2002, 761.

28 Özellikle Piri Reis'in Castel Lombardo'yu tanıtırken kullandığı ifadeler, Efrenç Taife'sinin şahitliğini göstermesi gibi canlı tasvirleri, kent üzerine güncel bilgisine işaret etmektedir. Dolayısıyla Castel Lombardo ile ilgili bilgi sahibi olduğu anlaşımaktadır. Bu nedenle verdiği bilgileri güvenilirdir. Her ne kadar Lombard ile Bombard 
Belki gerçekten de kaleyi fark etmemiştir ya da kaleyi denizciler için bir iz, bir nişan olarak eserinde bahsedecek önemde görmemiştir. Sadece Selinti Suyu'ndan bahsettikten sonra, daha batıya yönelmiş "ve o suyun tekrar gün batısı tarafında Ahmedce derler, deniz üzerine havale ada gibi bir yumru burnun üzerinde bir harap kale vardır, Ol kaleye Efrenç taifesi Kastalo Lombarda derler." demiştir. Bu satırları tekrar yazmaktan kasıt, Piri Reis'in de açık bir şekilde ifade ettiği gibi, Castel Lombardo'nun Selinti Suyu'nun batı tarafında olduğunu bir kere daha vurgulamaktır $^{29}$. Çünkü Selinti Suyu'nun batı tarafında olan, deniz üzerine sarkan ve ada gibi bir görünüm arz eden tek yer lotape (Aydap) olarak adlandırılan kenttir.

Piri Reis buna ek olarak, kalenin denize sarkmış bir ada ve top taşı (gülle) şeklinde yumru bir burnun üzerine inşa edilmiş olduğunu belirtmiştir. Aslında bugün hala, lotape harabelerinin üzerinde bulunduğu kayalık, kara tarafından bakıldığında, top gibi yumru bir görünüm sunmakta

dır (Fig. 3). Bu durum aslında lotape'nin Castel Lombardo/C. Ubaldo olduğuna dair bir işarettir, zaten Selinti Suyu'ndan sonra Alanya'ya kadar kıyı şeridi genellikle kumsal olarak devam etmektedir. Denize uzanmış, top şeklinde bir kayalık ya da herhangi bir kayalık üzerinde lotape'den başka bir kale yoktur. Bilinen yerleşimlerden olan Syedra ve Laertes iç kesimlerde yer almaktadır. Dolayısıyla Piri Reis'in tanımına uyan sadece bir yer vardır o da lotape'dir. Piri Reis ayrıca Alanya ile Castel Lombardo'nun arasını yirmi deniz mili olarak belirtmektedir. Mil hesabı konusunda tutarlı bir cetvel bulamasak da Osmanlı'da XX. yüzyılda bir deniz

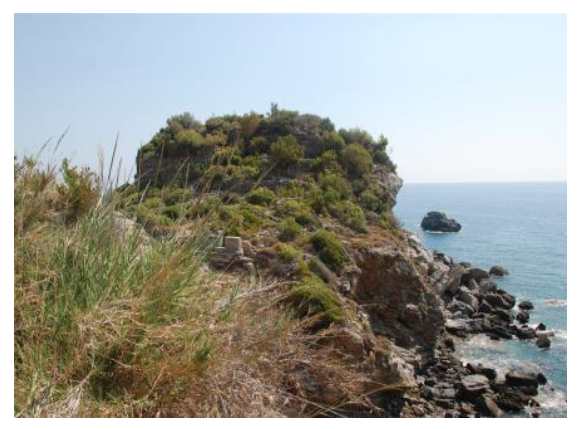

Fig. 3. İotape (Kuzeyden genel görünüm 28.07.2014). milinin 1667 metreye denk geldiği bilinmektedir. Buna göre 20 deniz mili yaklaşık olarak 33 km etmektedir ki bu da iki konum arasındaki uzaklıkla birebir örtüşmektedir. Ancak başka bir hesaba göre yirmi deniz mili 37 km'ye (1 mil: 1856 m) ya da başka bir hesaba göre 15 km'ye (1 mil: 758 m) denk düşmektedir ${ }^{30}$. Açıkçası bu konuda kesin bir kanaatte bulunmak zor gözükmektedir ${ }^{31}$.

Bunların dışında lotape'ye dair sunabileceğimiz bir başka kanıt ise Piri Reis'in haritasında ortaya çıkmaktadır. Piri Reis haritalarını kuşbakışıyla çizmiştir. Birkaç örnek vermek gerekirse Finike ve Kaledran Körfezi neredeyse bugünkü kuşbakışıyla aynı olarak çizilmiştir ${ }^{32}$ (Fig. 4-5). Iki tepe üzerinde çizdiği ve Kızlar Hisarı olarak anılan yer ise, muhtemelen Ortaçağ'da Antiocheia olarak adlandırılan kaledir ${ }^{33}$. Son olarak bahsedeceğimiz benzerlik ise bugünkü lotape ile haritadaki Kastalo Lombardo'yu (Ahmedce) karşılaştırdığımızda ortaya çıkmaktadır (Fig. 6).

Kale ile ilgili olarak elimizdeki en eski tarihli metin ve harita, Castel Lombardo/C. Ubaldo'nun lotape olduğunu göstermektedir. Daha önce belirttiğimiz gibi bölgede denize havale, ada gibi, top şeklinde kale olarak sadece lotape vardır. Bununla birlikte XVIII. yüzyıl başlarından itibaren bazı sözlüklerde bu makaledeki iddianın aynısı dile getirilmiştir.

kelimesini karıştırdığı anlaşılsa da.

29 Selinti Kalesi suyun doğu tarafındadır. Piri Reis ise Castel Lombardo için ırmağın batısını işaret ediyor.

30 Halaçoğlu 1995, 412; Kallek 2005, 54.

31 M. Sanudo ise Castel Lombardo'dan Alanya'ya 10 deniz mili mesafe olduğunu belirtir. Sanudo 2011, 148.

32 Aslında Piri Reis'in çoğu çizimi bugünkü kuşbakışı görüntüye uygundur. Kekova ve Porto Ceneviz vd. gibi çok fazla girintili çıkıntılı limanların bile, çizimleri gerçeğiyle önemli derecede benzerlik göstermektedir.

33 Hild-Hellenkemper 1990, 408. 


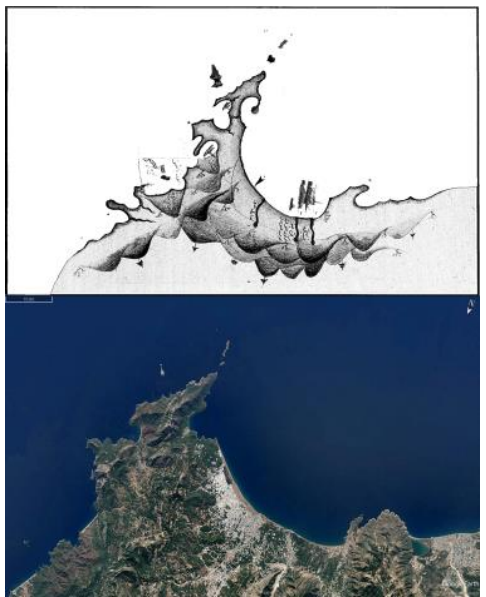

Fig. 4. Piri Reis'in çizdiği Finike ve civar ile bugünkü kuşbakışı görünümün karşılaştırılması.

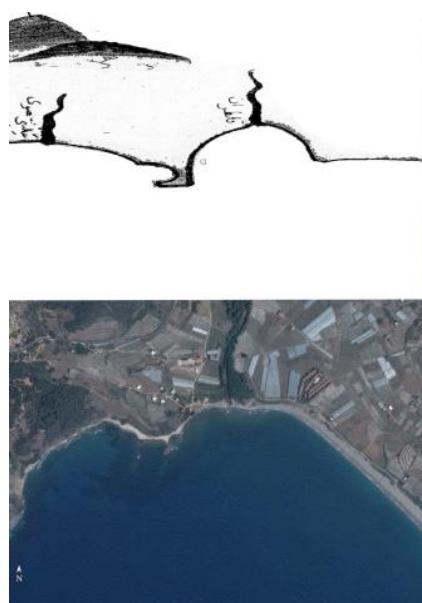

Fig. 5. Piri Reis'in çizdiği Kaledıran Körfezi ile bugünkü kuşbakışı görünümün karşılaştırılması.
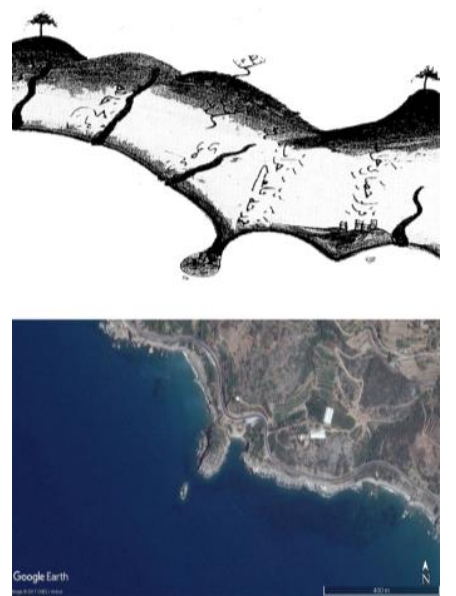

Fig. 6. Piri Reis'in Castel Lombardo (Ahmedce) çizimi ile bugünkü İotape'nin (Aydap) kuşbakışı görünümününkarşılaştırılması.

Bu nedenle, Piri Reis'in tanımını kullanarak yeni bir kanıt sunmak dışında Castel Lombardo/C. Ubaldo'nun lotape olduğu iddiasının yeni olmadığı söylenmelidir. 1730'da M. Bruzen L. Martiniere, hazırladığı coğrafya sözlüğünde "Castel Lombardo, Kıbrıs'ın karşısında Anadolu'nun güney sahilinde küçük bir kasabadır ... Eski lotape olduğuna inanılıyor" bilgisini paylaşmıştır ${ }^{34} .1828$ yılında hazırlanan yeni bir evrensel coğrafya sözlüğünde ise aynı bilgiler verilmiştir ve kentin lotape olması gerektiği üzerinde durulmuştur ${ }^{35}$. Ancak yine de eldeki verilerin yeterli olduğunu söylemek zordur. Çünkü en eski tarihi vesika Piri Reis'in çizdiği harita ve yazdıklarıdır ${ }^{36}$. Piri Reis'in bölgeden geçtiği dönem ise bölgedeki şehirlere isimler veren italyanların etkinliklerinin az olduğu bir döneme denk gelmektedir. Bölgedeki kentlerin isimlerinin İtalyancaya doğru değişimi XIII. ve XIV. yüzyılda yaşanan bir gelişmedir ${ }^{37}$. Piri Reis ise bölgeden XVI. yüzyılın ilk yarısında geçmiş olmalıdır. Ancak burada Piri Reis'in kullandığı bir cümle önemlidir. Piri Reis, Ahmedçe kalesi için Efrenç Taifesinin şahitliğini göstererek "Ol kaleye Efrenç taifesi Kastalo Lombarda derler" demiştir. Sanki Batııların o dönemde hala Kastalo Lombardo ismini kullandıklarına şahit olmuş gibidir.

\section{Sonuç}

Sonuç olarak eldeki tarihsel verilerin yetersiz olduğunu bir kere daha ifade etmekle birlikte; Castel Lombardo'nun ve Castel (Cape) Ubaldo'nun tek bir yer olduğunu ve buranın da Alanya veya Selinti değil de, ikisinin arasında bir yer olması gerektiğini belirtmek gereklidir. Şimdilik Piri Reis'ten ve geç dönem coğrafya sözlüklerinden hareketle kent için en uygun konumun ise lotape olduğu görülmektedir.

34 Martiniere 1730, 367.

35 Nuovo Dizionario 1828, 138.

36 Marino Sanudo ve Carte Pisane'de geçen Salmonde de kentin konumunu belirlemek konusunda yardımcı olmaktadır. En azından Castel Lombardo'nun Selinti olma ihtimalini zayıflatmaktadır.

37 Redford 2008, 48. 


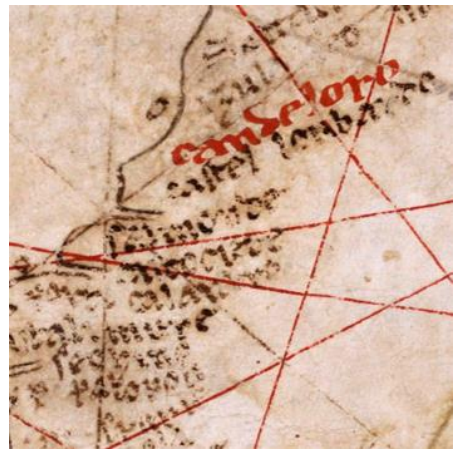

Fig. 7. Carte Pisane 13. Yüzyıl sonları:

Candeloro (Alanya), Castel

Lombardo, Salmonde, Antioceta, Calandro.

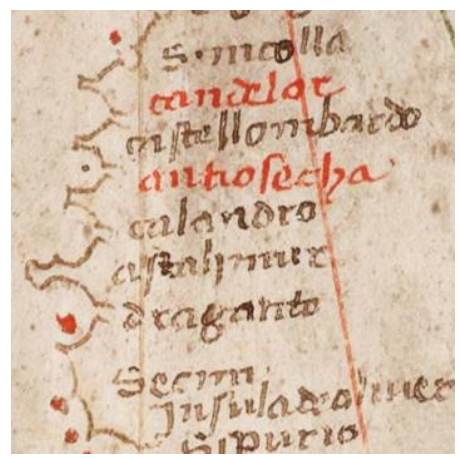

Fig. 10. Pierro Roselli 1462:

Candelor, Castellombardo, Antiocetha, Calandro, Stalimure.

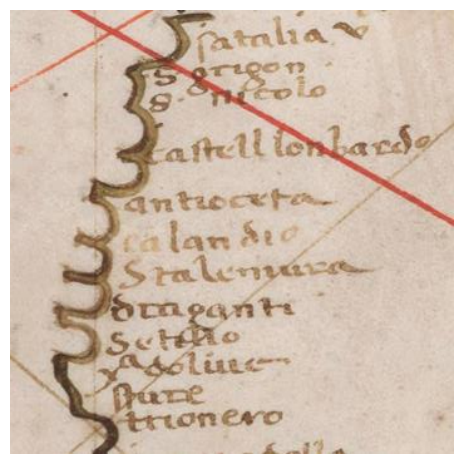

Fig. 13. Hieronymus Verrazano 1524: S. Nicolo, Castelllonbardo, Antioceta, Calandro.

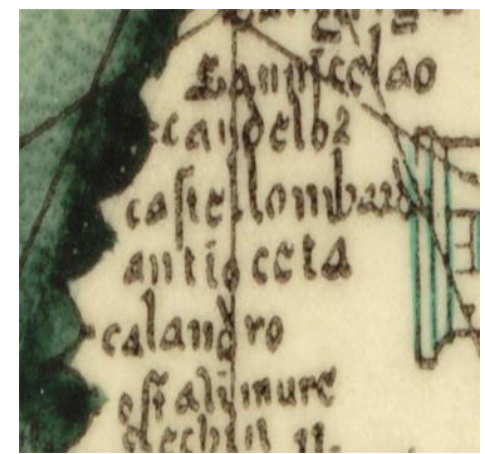

Fig. 8. Abraham Cresques Atlas de Cartes Marines (Atlas Catalan) 1375: Candelor, Castellombardo, Antioceta, Calandro.

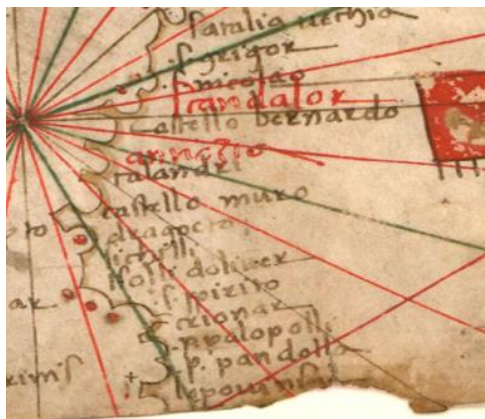

Fig. 11. Petrus Russus 1516: Scandalor, Castello Bernardo, Antioceta, Calandri.

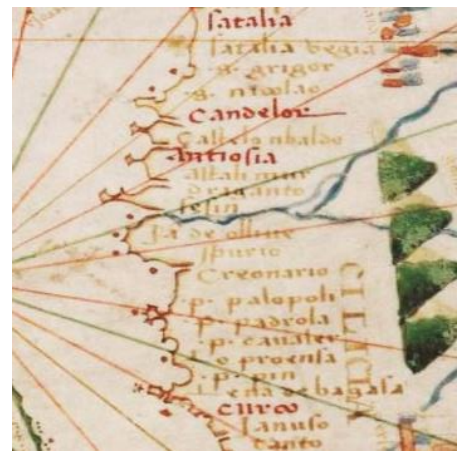

Fig. 14. Maggiolo Giacomo 1563:

Candelor, Castelonbaldo, Antiocia, Stalimure.

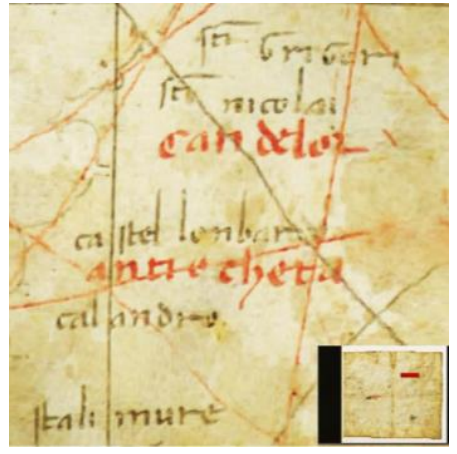

Fig. 9. Petrus Vesconte 1313: Candelor, Castel Lonbard, Antiocheta, Calandro.

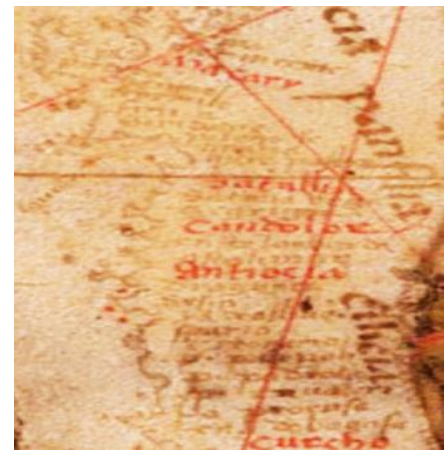

Fig. 12. Vesconte Maggiolo 1516: Candelor, Castel Lombardo, ... , Antiocia.

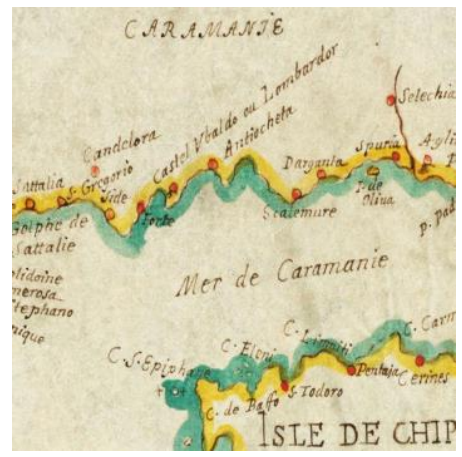

Fig. 15. Pierre Duval 17. Yüzyıl:

Candelor, Side, Forte, Castel

Ubaldo ou Lombardor, Antiocheta, Scalemure, Dranganta. 


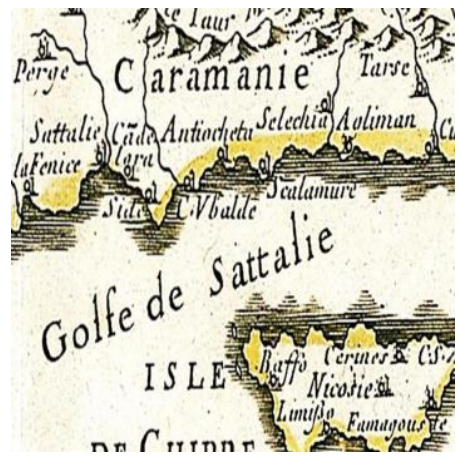

Fig. 16. Pierre Duval 1668: Sattalie, Cadelara, Side, C.Ubalde, Antiocheta, Scalemure.

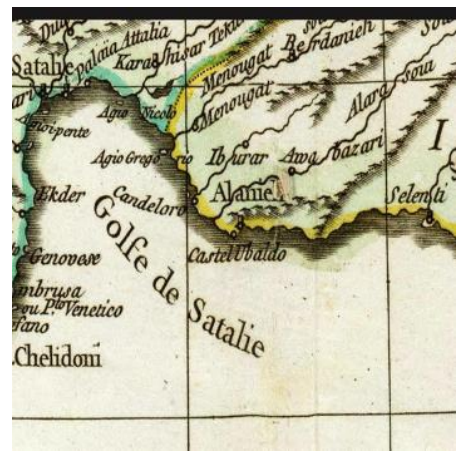

Fig. 19. Anville, Jean Baptiste Bourguignon d 1760: CandelorAlanie, Castel Ubaldo, Selenti.

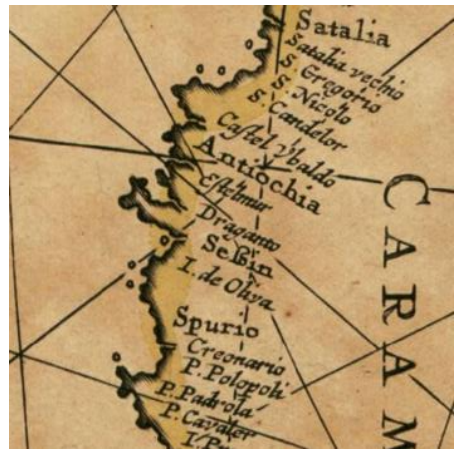

Fig. 17. Arnold Colom 1668: S. Candelor, Castel Ubaldo, Antiochia, Estelmur, Dranganto.

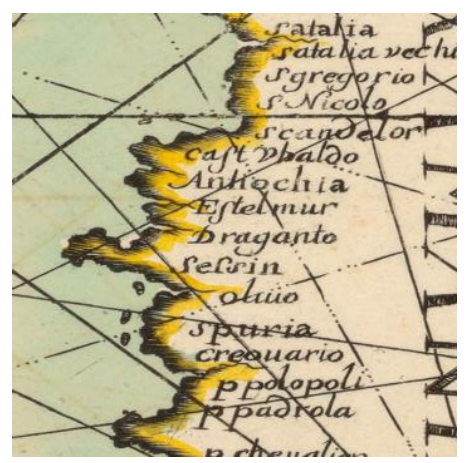

Fig. 20. Henry Michelot 1713: Scandelor, Cast Ubaldo, Antiochia, Estelmur, Draganto.

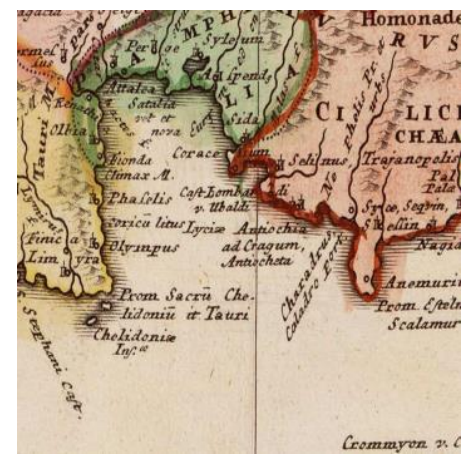

Fig. 22. Johann Matthias Hase 1743: Coracesium (Alanya), Selinus, Cast Lombardi v. Ubaldi, Antiochia ad Cragum, Charadrus Caladro.

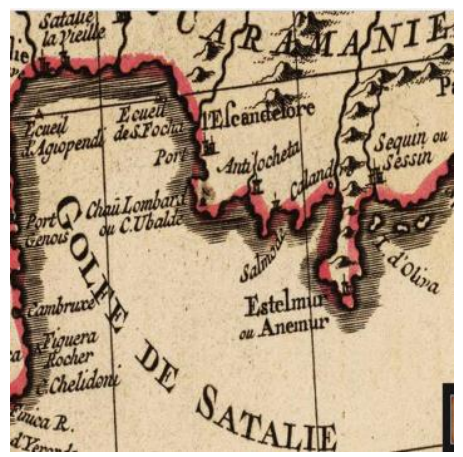

Fig. 18. Guillaume de L'isle 1707: L'Escandelor, Chau Lombard ou C. Ubalde, Antiocheta, Salmode, Calandro.

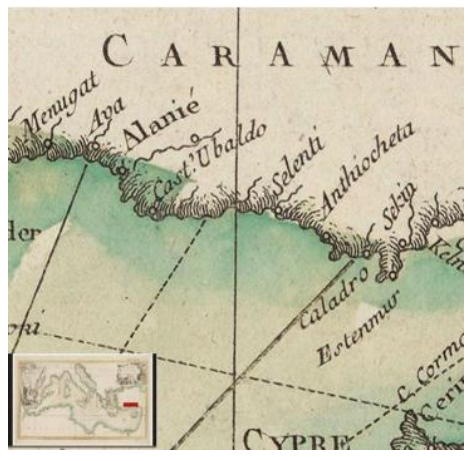

Fig. 21. Charles-Rigobert Bonne 1780: Alanie, Cast Ubaldo, Selenti, Antiocheta, Calandro. 
Alishan 1899

Beaufort 1818

Duggan 2017

Flemming 1964

Halaçoğlu 1995

Hellenkemper-Hild 2004

Heyd 1885

Hild - Hellenkemper 1990

Kallek 2005

Konyalı 1946

Kretschmer 1909

Leake 1824

Lloyd Rice 1989

Martiniere 1730

Mason 1989

Nuovo Dizionario 1828

Rauh et al. 2009

Piri Reis 2002

Poumarede 2010

Redford 2008

Sanudo 2011

Sarıcaoğlu 2002

Smith 1854

Tomaschek 1891

\section{Mehmet Ali BOZKUŞ}

\section{BİBLIYOGRAFYA}

Leon M. Alishan, Sissouan, ou L'Arméno-Cilicie : description géographique et historique, avec cartes et illustrations / Traduit du Texte Arménien, Venise 1899.

Francis Beaufort, Karamania, A Brief Description of the South Coast of Asia Minor, London 1818.

T. Mikail P. Duggan, "Depicting and Charting the Southern Coastline of Anatolia - Record of the Later Toponyms of Phaselis: Palyopoli-Paleopolis, Tekiroba, Gironda-Phionda-Fironda-Fionda - The 1812 Report of Rapid Coastal Erosion - The (Doubtful?) Islands and Evidence leading Towards a Date for the Collapse of the Upper Courses of the Inner Harbour Arm at Ancient Phaselis, Antalya", PHASELIS III (2017) 1-48.

http://dx.doi.org/10.18367/pha.17001.

Barbara Flemming, Landschaftsgeschichte von Pamphylien, Pisidien und Lykien im Spätmittelalter, Wiesbaden 1964.

Yusuf Halaçoğlu, "Fersah", TDViA, C.12, s.412.

Hansgerd Hellenkemper- Friedrich Hild, TIB 8 Lykien und Pamphylien, Wien 2004.

W. Heyd, Histoire Du Commerce Du Levant Au Moyen Age, Paris 1885.

Friedrich Hild-Hansgerd Hellenkemper, TIB 5 Kilikien und Isaurien, Wien 1990.

Cengiz Kallek, "Mil”, TDVIA, C.30, s.53-54.

Ibrahim Hakkı Konyalı, Alanya Tarihî-Turistik Kılavuz, İstanbul 1946.

Konrad Kretschmer, Die italienischen Portolane des Mittelalters. Ein Beitrag zur Geschichte der Kartographie und Nautik, Berlin 1909.

William Martin Leake, Journal of A Tour in Asia Minor With Comparative Remarks On The Ancient And Modern Geography of That Country, London 1824.

Seton Lloyd ve D. Storm Rice, Alanya ('Alấiyya), Çev. Nermin Senemoğlu, Ankara 1989.

M. Bruzen La Martiniere, Le Grand Dictionnaire Geographique et Critique, Vol 2, Lahey 1730.

Roger Mason, "The Medici-Lazara Map of Alanya", Anatolian Studies, Vol. 39 (1989), 85-105.

Nuovo Dizionario Geografico Universale Statistico - Storico - Commerciale, Vol II, Venedik 1828

Nicholas K. Rauh - Rhys F. Townsend - Michael C. Hoff - Matthew Dillon Martin W. Doyle - Cheryl A. Ward - Richard M. Rothaus - Hülya Caner Ünal Akkemik - LuAnn Wandsnider -F. Sancar Ozaner - Christopher D. Dore "Life in the Truck Lane: Urban Development in Western Rough Cilicia" Jahreshefte des Österreichischen Archäologischen Institutes, Band 78 Wien 2009, s.253-312.

Piri Reis, Kitabı Bahriye, TTK, Ankara 2002.

Geraud Poumarede, Haçlı Seferleri'ne Son Çağrı, Yeniçağ Avrupası'nda Osmanlı Imgesi, Çev. İsmet Birkan, İstanbul 2010.

Scott Redford, Anadolu Selçuklu Bahçeleri, Çev. Serdar Alper, İstanbul 2008. Marino Sanudo Torsello, The Book of the Secrets of the Faithful of the Cross - Liber Secretorum Fidelium Crucis, Çev. Peter Lock, Farnham 2011.

Fikret Sarıcaoğlu "Kitâb-ı Bahriyye", TDVIA, C.26, s. 72-75.

William Smith LL. D., Dictionary Greek and Roman Geography, Vol 1, Boston 1854

Wilhelm Tomaschek, "Zur Historischen Topographie von Kleinasien im 
Mittelalter", Sitzungsberichte der Philosophisch-Historischen Classe der Kaiserlichen Akademie der Wissenschaften, Wien 1891.

Kullanılan Haritalar

Carte Pisane XIII. Yüzyıl

Abraham Cresques, Atlas de

cartes marines, dit [Atlas

catalan] Katalan Atlas 1375

Petrus Vesconte 1313

Piero Roselli 1462

Petrus Russus 1516

Vesconte Maggiolo 1516

Hieronymus Verrazano 1524

Maggiolo Giacomo 1563

Pierre Duval XVII. Yüzyıl

Pierre Duval 1668

Arnold Colom 1668

Guillaume Delisle 1707

Anville, Jean Baptiste

Bourguignon d, 1760

Henry Michelot 1713
(Erişim tarihi 15.09.2017)

http://gallica.bnf.fr/ark:/12148/btv1b52503226n/f1.item

(Bibliothèque nationale de France, département Cartes et plans, GE B-1118 (RES)

http://gallica.bnf.fr/ark:/12148/btv1b55002481n/f9.image

(Bibliothèque nationale de France, Département des manuscrits, Espagnol 30)

http://gallica.bnf.fr/ark:/12148/btv1b5901108m/f8.item

(Bibliothèque nationale de France, département Cartes et plans, CPL GE DD-687 (RES)

http://gallica.bnf.fr/ark:/12148/btv1b53064888c/f1.item

(Bibliothèque nationale de France, département Cartes et plans, GE C-5090 (RES)

http://gallica.bnf.fr/ark:/12148/btv1b5901090c/f1.item

(Bibliothèque nationale de France, département Cartes et plans, CPL GE B-1425 (RES)

http://dpg.lib.berkeley.edu/webdb/dsheh/heh_brf?Description=\&CallNum ber $=\mathrm{HM}+427$

http://gallica.bnf.fr/ark:/12148/btv1b53074817b/f1.item

(Bibliothèque nationale de France, département Cartes et plans, GE C-5100 (RES)

http://gallica.bnf.fr/ark:/12148/btv1b550070685/f1.item

(Bibliothèque nationale de France, département Société de Géographie, Sgy 1704 Rés)

http://gallica.bnf.fr/ark:/12148/btv1b5905593k/f1.item

(Bibliothèque nationale de France, département Cartes et plans, CPL GE SH $18 \mathrm{E}$ PF 63 P 17 RES)

http://gallica.bnf.fr/ark:/12148/btv1b53027468t/f1.item

(Bibliothèque nationale de France, département Cartes et plans, GE D-12010)

http://gallica.bnf.fr/ark:/12148/btv1b5962749k/f1.item

(Bibliothèque nationale de France, département Cartes et plans, CPL GE DD2987 (9616 B)

http://gallica.bnf.fr/ark:/12148/btv1b53033671s/f1.item

(Bibliothèque nationale de France, département Cartes et plans, GE D-15169

http://gallica.bnf.fr/ark:/12148/btv1b530092002/f1.item

(Bibliothèque nationale de France, GEC-6131)

http://gallica.bnf.fr/ark:/12148/btv1b530281039/f12.item

(Service historique de la Défense (Marine), MV SH 101)

Charles-Rigobert Bonne 1780 http://gallica.bnf.fr/ark:/12148/btv1b84933527/f1.item

(Bibliothèque nationale de France, département Cartes et plans, GE D-15502)

Johann Matthias Hase 1743 http://gallica.bnf.fr/ark:/12148/btv1b8592782p/f1.item

(Bibliothèque nationale de France, département Cartes et plans, GE DD-2987 (6502) 